\title{
Managing Distributed Innovation Processes in Virtual Organizations by Applying the Collaborative Network Relationship Analysis
}

\author{
Jens Eschenbächer, Marcus Seifert, and Klaus-Dieter Thoben \\ BIBA - Bremer Institut für Produktion und Logistik GmbH, Hochschulring 20, \\ 28359 Bremen, Germany \\ esc@biba.uni-bremen. de
}

\begin{abstract}
Distributed innovation processes are considered as a new option to handle both the complexity and the speed in which new products and services need to be prepared. Indeed most research on innovation processes was focused on multinational companies with an intra-organisational perspective. The phenomena of innovation processes in networks - with an inter-organisational perspective - have been almost neglected. Collaborative networks present a perfect playground for such distributed innovation processes whereas the authors highlight in specific Virtual Organisation because of their dynamic behaviour. Research activities supporting distributed innovation processes in $\mathrm{VO}$ are rather new so that little knowledge about the management of such research is available. With the presentation of the collaborative network relationship analysis this gap will be addressed. It will be shown that a qualitative planning of collaboration intensities can support real business cases by proving knowledge and planning data.
\end{abstract}

Keywords: Distributed innovation processes, Virtual organizations, collaborative network relationship analysis.

\section{Introduction}

Companies are forced to shorten and improve their innovation cycles in order to stay competitive in the global market [1] and [2]. A good example for a short innovation cycle in a new market segment shows the introduction of the iPhone. Apple was able to create from the scratch a world-wide successful mobile phone. The success of the iPhone is based on an attractive design, the concept of being permanently online and a new and innovative user interface technology [3]. The question is how Apple was able to manage these challenges successfully without being active in the mobile phone industry before. The approach in this case was to integrate experienced partners with complementary core competencies into a collaborative network. The aim of this collaboration was to design a new and innovative product by sharing and combining previously isolated and distributed knowledge. This successful example demonstrates the potential impact of collaborative networks on innovation projects. As unpleasant side effect, collaboration within innovation projects always includes an increasing 
number of risks. Examples for those risks are the lack of synchronization due to the distribution of tasks and responsibilities, competing goals of the collaborating partners or the possible loss of intellectual property of certain partners.

Having the benefits on the one hand and the risks of distributed innovation processes on the other hand, the question is how to exploit the collaboration benefits while coping with the risks. The principle of the Collaborative Network as new organisational framework has been introduced by many authors [4], [5], [6] and [7]. As a special type of the Collaborative Network, the Virtual Organisation (VO) represents the task specific, short term alliance between independent companies. Due to its temporary character, the $\mathrm{VO}$ is the suitable collaboration type to create collaborative innovations based on identified business opportunities [8]. Here the analysis of collaborative relationships is a very important subject which needs further investigations.

The paper proposes an approach to plan and to maintain the individual relationships within a VO on an operational level, based on a quantitative characterization of these relationships. Specific attention will be paid to both the conceptual presentation and a basic mathematical representation of the approach. The application of the proposed approach, the so called "Collaborative Network Relationship Analysis (CNRA) will lead to an improved operational management of distributed innovation processes in Virtual Organizations. Finally, the CNRA is evaluated in an industrial case of a Virtual Organization in the automotive supplier industry.

\section{Perspectives on Collaborative Network Relationship Analysis Supporting Innovation Processes}

Innovation management can be seen from two perspectives: While the strategic perspective covers mainly innovation strategy and innovation organization (Gerpott 1999), the operational perspective deals with the design and management of innovations projects. A lot of research has been done to conduct innovation processes on the operational level. Approaches such as the Stage Gate method [9], the Innovation Funnel, Fuzzy Front end [10] or Process Diagram [11] have been introduced to maintain mainly innovation processes on an intra-organizational level. Distributed innovation processes in Collaborative Networks and especially in Virtual Organisations (VO) have been subject of several recent PHD thesis [12]. However the results are still in a nearly stage in comparison to the large amount of research analyzing intra-organisational innovation processes e.g. in multinational companies [13]. Additionally, most of this research is dedicated towards the optimization of the strategic perspective [14]. So far, an approach to better understand the operational issues of managing distributed innovation processes in $\mathrm{VO}$ is missing.

The operational management of distributed innovation processes in Virtual Organizations can separated in early stage innovation phases (focus on ideas management [15] and late innovation phases (focus on innovation project management [16]. Whereas the financial risks in the early phase are comparatively low, the management of distributed innovation processes becomes in later phases a decisive issue due to the increasing usage of resources and necessary investments. Consequently an approach is needed which both plans and controls the distributed innovation processes in the late phase. 
Whereas the single site company as well as stabile Supply Chains or Extended Enterprises led by an OEM do have homogenous and synchronized goals and motives within an innovation project [12], in VOs the objectives and interest of the partners are normally very divergent and heterogeneous due to the independency of the partners. The distributed innovation processes in the Virtual Organization are based on the achievement of competing and synergetic objectives in the same time and the share of the related risks.

Consequently, the understanding and consideration of heterogeneous interests of the partners (nodes) within the VO as well as the harmonization of these interests when setting up the relationships (links) between the partners are essential success factors of innovation processes in VOs. The intensity of the bilateral relationships between the VO partners needs to be designed according to the specific collaboration needs of these partners during the entire innovation project.

\section{Analysis of Collaborative Relationships}

The analysis of collaborative network relationships has been introduced with the developments of the social network analysis [17]. The social network analysis was focusing on quantitative approaches analyzing nodes and edges. Recently qualitative approaches have been developed to supplement the quantitative approaches. In the following sections quantitative and qualitative approaches will be described and potential and limits will be illustrated.

\subsection{Quantitative Approaches}

The application area of the network analysis is very broad [18]. Especially the developments in the social network analysis led to many approaches (Wassermann and Fausst 1994) and a high number of tools [19]. Meanwhile business oriented study results are available focusing on the application of the methods of the network analysis in companies [20]. The authors were analyzing intra-organisational networks from the BASF corporate group. A recent study discusses the analysis of ICT aspects in the Siemens Corporation [21]. Ellmann has analysed two indicators out of many in the framework of the quantitative network analysis. Specifically she has studied the density and centrality of nodes within a network. Consequently the methods of the social network analysis arrived in the framework of business management. In general the quantitative network analysis is divided into three phases: data acquisition, data representation and data analysis [20]. Indeed there are different methods available to collect, structure and evaluate quantitative data [22].

The quantitative network analysis captures network structures by using mathematical calculations, which implies a very formalistic way of handling network relationships. In fact this has been the basis for a lot of criticism towards quantitative procedures of the network analysis [20]. Basically two points can be summarized:

- Too Static: Due to the different measurement of various characteristics, the procedures of network analysis are able to construct networks in deep according to their structure but content, and dynamics of relationships cannot be captured. Additionally, lacking consideration of context awareness seems to be a problem [23]. 
- Difficult translation from experiences into numbers: As a matter of fact the quantitative description necessary to operational qualitative characteristics by using indicators is to a certain extent impossible. Indeed an actor which is acting a long time already in the network can be a layman considering network analytic methods. But - and this is important - such a layman can most probably understand and translate the network behaviour due to his experience better than every network analyst.

The quantitative methods for network analysis can be used specifically in those situations in which already a lot of knowledge about the behavior of the network is available. This knowledge can be used within a precise analysis leading to concrete results. Additionally a narrow and precise research question should be formulated to make it understandable. In case of rough investigated research fields and non precise research questions the quantitative methods and not recommended. The research field should not have many explorative elements.

\subsection{Qualitative Approaches}

Indeed it is a question of the massive criticism towards the quantitative network research that qualitative network analysis is getting increasing attention. In comparison to quantitative approaches the usage of qualitative approaches is still in its beginning.

Qualitative methods for network analysis aim to transfer the layman theories of members of the virtual organisation about relationship constellations in the network analytical outward perspective. Exactly this transfer can be seen as the main objective of qualitative network research methods.

When it is made possible to interpret the actor's behavior in networks for outsiders in a transparent manner, then the network analysis touches ground, which were closed so far [23]. For this reason the qualitative network analysis can give direction for the network analytical research in general. Instruments which can capture and analyse both dynamic and temporal changes in the network can be seen as biggest conceptual challenge for research. The qualitative network research offers opportunities for doing this [18].

The qualitative network analysis can in the same manner as for the quantitative be divided in data acquisition, data representation and data analysis. The main difference lies in the kind of instruments and the respective questions. Naturally the qualitative network approaches are analyzing different instruments focusing less on mathematical accuracy but more on gathering and understands layman theories.

A nice overview about more qualitative tools for network analysis can also be found at [19]. Additionally, Hollstein [18] discusses the whole range of tools.

In order to achieve transparency by using qualitative research methods, the network researcher must enter the subsurface structure and the social reality of the network actors. This complex task gets even more difficult, because there is no common language between network actor and network researcher. While the network researcher is able to capture emotional and systematic characteristics of networks and transfer that to a comprehensive language, actors within the network might not understand this. Contrariwise it will be very difficult to translate layman theories into a network describing formal language. This is especially true because there is no commonly accepted network language which offers much room for interpretation [23]. 
The qualitative network analysis highlights context conditions such as trust and emerging standards. The analysis can be used as a form for exploring new issues such as innovation processes. Additional qualitative network analysis methods can be used for interpreting each actor, subjective perceptions and guided orientations [18]. However the results of the qualitative network analysis are always subjective because they are based on prognosis and estimates. In the case of this chapter both procedures are sued to investigate innovation processes.

\section{Concept of the Collaborative Network Relationship Analysis (CNRA)}

This chapter discusses the CNRA as qualitative approach to support the planning and maintenance of innovation processes.

\subsection{Concept and Method}

The concept of collaborative network analysis is based on some assumptions and basic conditions. The main assumption is that a group of companies have the intention to cooperate. In other words they are not carefully analyzing "make-or-buy" or deciding if collaboration is the right way to do the things. The SME have simply decided to collaborate in order to bring together resources, Knowledge and core competencies. The basis for the collaborative network analysis is the identification of the needed collaborative relationships. In a second step the collaboration intensity have to be specified. Another assumption is that the collaboration intensity varies substantially within the different tasks in cooperation. Thirdly it is necessary to forecast the needed interactions differentiated in 6 categories. Finally these issues have been supplemented by a model to analyze innovation processes (see Figure 1).

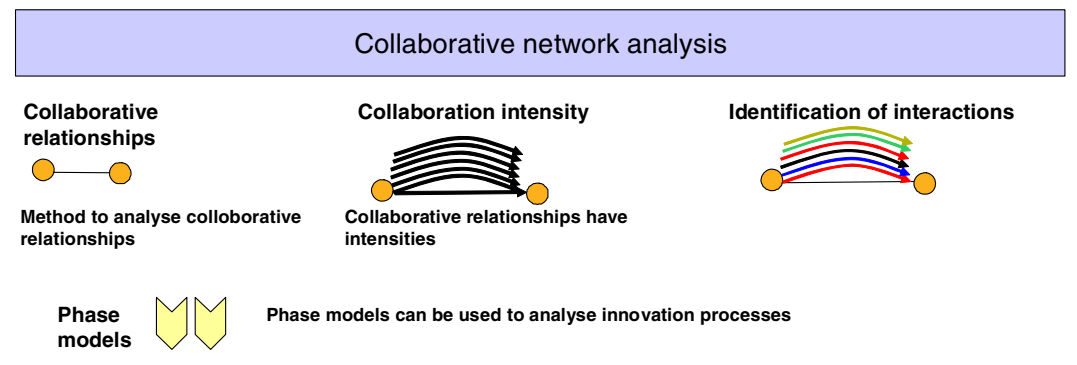

Fig. 1. Concept of the collaborative network analysis

Based on the concept of Figure 1 the collaborative relationships have to be forecasted and analyzed. The aim is to identify all three the relationships, the interactions within these relationships and the optimal collaboration intensity between the partners. Based on these conceptual ideas the collaborative network analysis method has been proposed which is shown in Figure 2. 


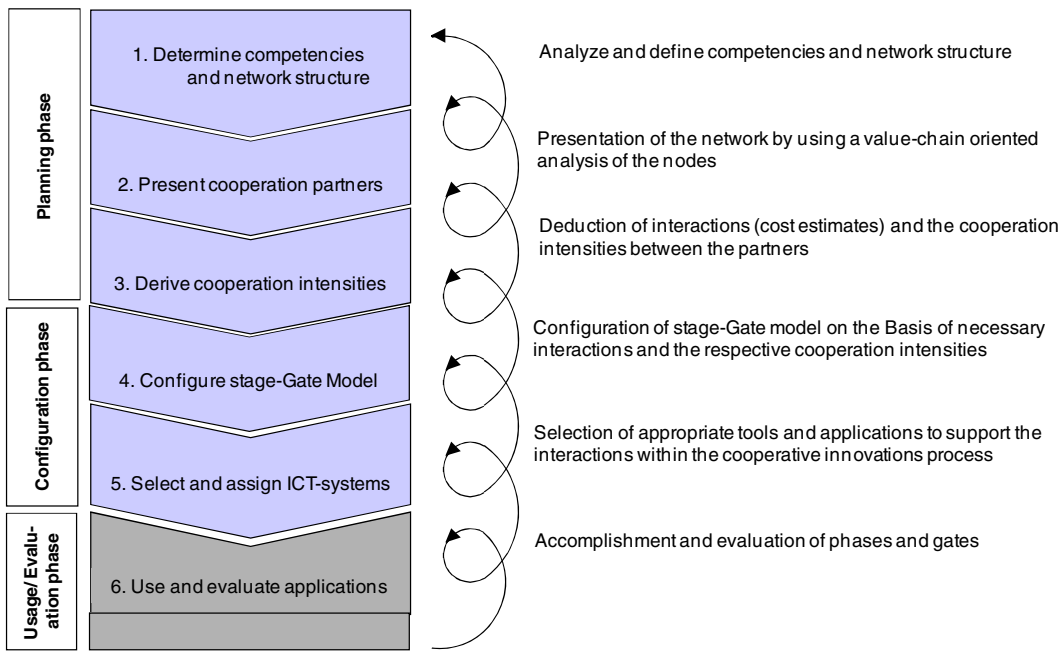

Fig. 2. Method of Collaborative network analysis (CNRA)

Basically the method differentiates three phases:

- Planning phase: in this phase the stage for cooperation is being set.

- Configuration phase: In this phase stage-gate model will be build on the basis of collaborative relationships and ICT system will be selected.

- Usage/Evaluation phase: In this phase the success of the forecasting results will be evaluated.

In the following the three sub-phases of the planning phase of the method is briefly described:

1. Determine competencies and network structure: First the necessary competencies and the network structure need to be identified. This is done based on the identification of collaborative relationships, their respective interactions with their divers' intensities.

2. Present cooperation partners: In this step a value chain model is being used to analysis the competencies of the nodes.

3. Derive cooperation intensities: In this step the deduction of cooperation intensities is taking place which finally led to the specification of cooperation intensities on the level of interactions.

In the following two sub-phases of the configuration phase of the method is briefly described:

1. Configure stage-gate model: In this step the stage gate model is build on the basis of collaborative relationships, intensities and interactions.

2. Select and assign ICT-systems: Select appropriate ICT-tools to support the innovation processes. 
Finally the evaluation phase - sub-phase 6 - use and evaluate applications - analysis if the forecast and planning of the VO was successful or not. Here the focus is on the quality of the forecast of collaborative relationships and the forecast of ICT tools.

\subsection{Derive Collaboration Intensity: Application in a Case Study}

The ideas of collaborative relationships have been introduced in the previous section. In order to develop the collaboration intensity a five-step approach has been developed which links the needed information towards the identification. Figure 3 shows the developed approach to specify the collaborative relationships.

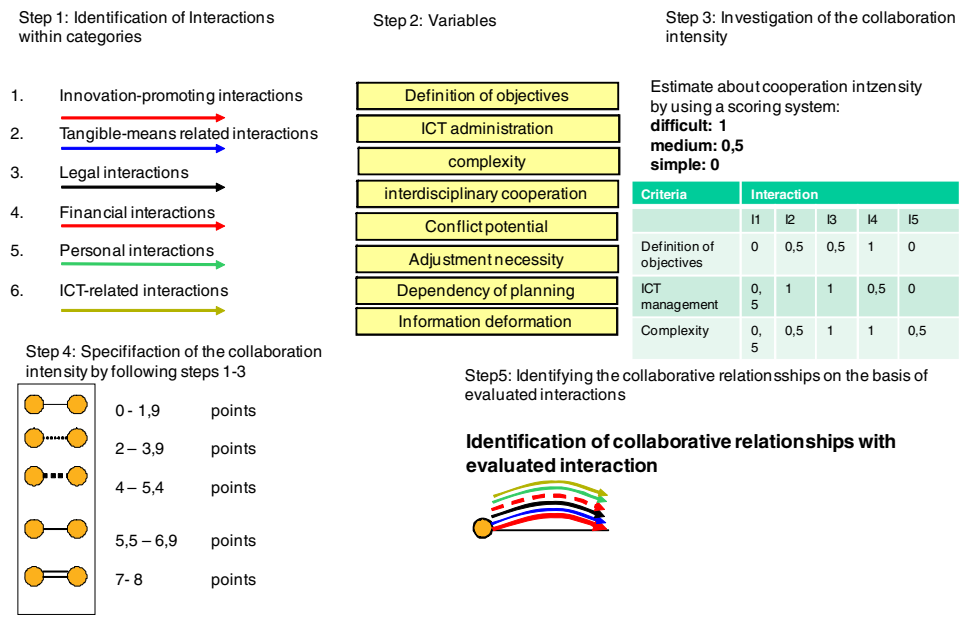

Fig. 3. Approach to specify the collaborative relationships

1. All identified interactions within the forecasted VO are collected. Additionally the interactions will be specified towards one of the six categories.

2. The variables are selected.

3. The variables are evaluated by using a simple method. An estimated about the collaboration intensity is investigated by a simple scoring system. This scoring provides ideas about the potential difficulty to conduct the interaction.

4. The collaboration intensity will be specified on the basis of the scoring result from the previous step.

Finally the collaborative relationships are specified by using the evaluated interactions.

\subsection{Exemplary Usage of the CNRA Method}

Based on the description of the previous section an example for the application of the CNRA method is presented here. In sub-phase 1 the competencies and the number of network partners have been investigated. Four partners collaborate within an innovation project. Altogether five competencies have been selected. The different partners 
do bring in such competencies in the collaboration. In the first place such competencies are based on interactions which are so far neither coupled nor further specified. The logical structure of the connections between the different competencies is shown in Figure 4. Here the interactions are not evaluated in a quantitative or qualitative manner. Finally Figure 4 presents the result of sub-phase 3 of the planning phase. Basically the approach has been applied to identify the type of interactions, the intensity of interactions as basis for and the interaction value chain. This Figure illustrates the forecasting approach clearly. The main objective is the identification of the needed competencies with the SME collaboration and to evaluate them. The color codes indicates the different interaction types.

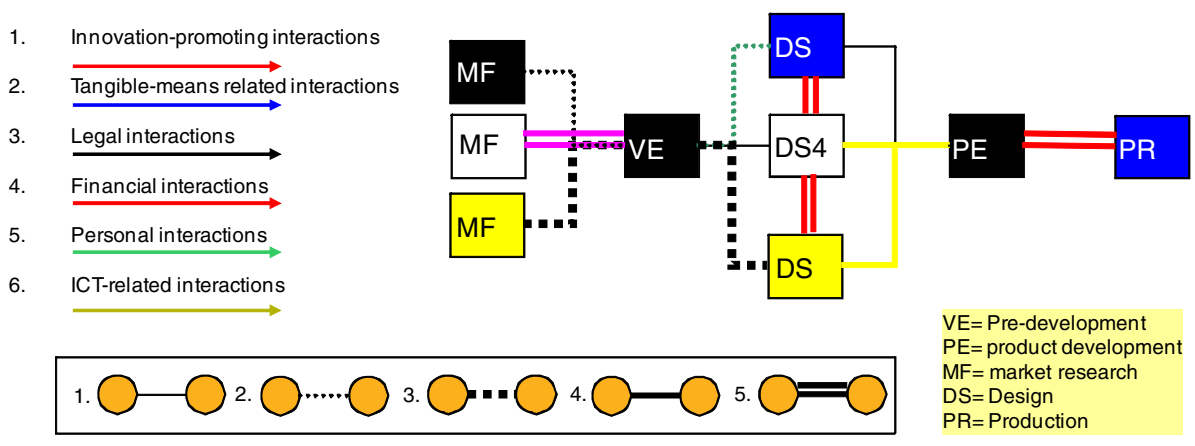

Fig. 4. Specification of collaboration intensity

The collaborative network analysis provides a detailed way to better understand and forecast collaborative relationships. From an application point of view the method focuses on an operational support for innovation project. The results provide a detailed overview about the concept of collaboration intensity on the level of edges between nodes.

\section{Results and Conclusions}

The method shall be used to support the forecasting innovation processes in VO. The CNRA focuses more on the forecasting of business developments. However both methods deliver ex ante suggestions of potential developments so they can be considered as explorative approaches. The results of the CNRA can be summarized as follows:

- Structural dimension: Short-term / mid-term planning of actors and their relationships; Network structure; Specification of necessary relationships, Roles of VO partners; Value chain structure

- Functional dimension: Design of distributed business process by using Porter Value chain model; Stage-Gate-Process; Collaboration intensity, Understanding of secondary value chain processes

In general the example illustrates a major improvement in their planning and forecasting activities by using the proposed approaches. 
- More transparency about log, mid- and short term planning,

- Awareness about the usefulness about the usage of a VBW,

- Clear scenarios about potential developments of cooperation projects by using the CNRA an

- Better understanding about the evolution and metamorphosis of VBE and their respective partners.

It can be summarized that the proposed concepts do support VO in their ability to conduct planning and forecasting in an open, collaborative environment.

Acknowledgements. The authors thank the partners and the European Commission for support in the context of the COIN project under contract number EU-FP7216256. For more information see http://www.coin-ip.eu/.

\section{References}

1. Gassmann, O., von Zedtwitz, M.: Trends and Determinants of Managing Virtual R\&D Teams. R\&D Management 33(3), 243-262 (2003)

2. Segarra, G.: The Advanced Information Technology Innovation Roadmap. Computers in Industry 40(11), 185-195 (1999)

3. Gassmann, O., Sutter, P.: Praxiswissen Innovationsmanagement. München, Carl Hanser Verlag (2008)

4. Camarinha-Matos, L.M., Afsarmanesh, H., Galeano, N., Molina, A.: Collaborative networked organizations - concepts and practice in manufacturing enterprises. Computers \& Industrial Engineering, Article in Press (2009)

5. Schuh, G., Lenders, M., Bender, D.: Lean Innovation. Auf dem Weg zur Systematik. Industrie Management 25(1), S.23-S.27 (2009)

6. Chesbrough, H.W.: Open Innovation. The New Imperative for Creating and Profiting from Technology. Harvard Business School Press, Boston (2003)

7. Eschenbächer, J., Graser, F., Hahn, A.: Governing Smart Business Networks by Means of Distributed Innovation Management. In: Verwest, P.-H., van Heck, E., Preiss, K. (eds.) Smart Business Networks, Berlin Heidelberg New York, pp. 307-323 (2005)

8. Seifert, M.: Unterstützung der Konsortialbildung in Virtuellen Organisationen durch prospektives Performance Measurement. Dissertation an der Universität Bremen. Bremen (2007)

9. Cooper, R.G.: Third Generation New Product Processes. The Journal of Product Innovation Management 11(1), S.3-S.14 (1994)

10. O'Sullivan, D., Cormican, K.: A Collaborative Knowledge Management Tool for Product Innovation Management. International Journal of Technology Management 26(1), 53-67 (2003)

11. Cormican, K.T.: Product Innovation Management for Networked Organisations, Dissertation, National University of Ireland, Galway (2001)

12. Hagenhoff, S.: Innovationsmanagement für Kooperationen - Eine instrumentenorientierte Betrachtung. Göttingen (2008)

13. Christensen, C.-M.: The Innovators Solution: Creating and Sustaining Successful Growth. Havard Business School Press, Boston (2003)

14. Boutellier, R., Gassmann, O., Zedtwitz, M.: Managing Global Innovation - Uncovering the Secrets of Future Competitiveness. Springer, Heidelberg (2008) 
15. Nyffenegger, F., Kobe, C.: IT-Unterstützung der frühen Phasen der Produkt-Innovation. Industrie Management 25, 45-49 (2009)

16. Herstatt, C., Verworn, B.: Management der frühen Innovationsphasen. 2. überarbeite und erweiterte Auflage, Wiesbaden, Gabler Verlag (2007)

17. Wassermann, S., Faust, K.: Social Network Analysis: Methods and Applications. Cambridge University Press, Cambridge (1994)

18. Hollstein, B.: Qualitative Netzwerkanalyse: Konzepte, Methoden, Anwendungen. In: Hollstein, B., Straus, F. (eds.) Wiesbaden. VS Verlag für Sozialwissenschaften (2006)

19. CASOS, http: //www.casos.cs.cmu.edu/computational_tools/tools.html

20. Rank, O.N.: Formale und informelle Organisationsstrukturen: Eine Netzwerkanalyse des strategischen Planungs- und Entscheidungsprozesses multinationaler Unternehmen. Wiesbaden, Gabler (2003)

21. Ellmann, S.: Management komplexer internationaler Projekte: Netzstrukturen, Governance und Handlungsempfehlungen. PHD-thesis (2008) (to be published)

22. Eschenbächer, J.: Gestaltung von Innovationsprozessen in Virtuellen Organisation durch kooperationsbasierte Netzwerkanalyse, PHD-thesis (2008) (to be published)

23. Renz, T.: Management in internationalen Unternehmensnetzwerken. Wiesbaden, Betriebswirtschaftlicher Verlag Dr. Th. Gabler (1998) 